\title{
Effect of Nanosilica on the Strength of Cement-based Grouping Materials
}

\author{
Mei Liang ${ }^{1, a}$, Wenxia $\mathrm{Li}^{1, \mathrm{~b}}$, Tingting Xu ${ }^{2, \mathrm{c}}$, Qingke $\mathrm{Zhou}^{1, \mathrm{~d}}$, Shengli Li $\mathrm{i}^{2, \mathrm{e}}$ \\ ${ }^{1}$ Zhengzhou University of industrial technology, Zhengzhou, Henan, 451199 \\ ${ }^{2}$ Zhengzhou university, Henan, 450002 \\ ${ }^{a}$ email, ${ }^{b}$ email, ${ }^{c}$ email, ${ }^{d}$ email, ${ }^{e}$ email
}

\begin{abstract}
Keywords: Nanosilica, Compressive Strength, Flexural Strength, Cement-Based Grouting Materials
\end{abstract}

\begin{abstract}
The grouting materials are widely used in construction materials for a long time and play an important role in the construction engineering. The flexural strength and compressive strength are the basic properties of cement based grouting materials. Therefore, the strength at a certain age of the cement-based grouping material with different contents of nanosilica was studied. The results showed that the flexural strength and compressive strength of the cement-based grouping materials increased with increasing nanosilica content when the content of nanosilica was lower. However, with larger dosage of nanosilica, the flexural strength and compressive strength of the cement-based grouping materials declined with increasing nanosilica content.
\end{abstract}

\section{Introduction}

Since the 1990s, people have incorporated nanomaterials to improve the performance of cement-based materials or to give them new performance to meet the ever-increasing technological needs of economic and social development [1-6]. For a long time, grouting material in the construction project is a kind of large amount of application, the use of a wide range of building materials [7-9].

From the current situation in some of the strength requirements of higher engineering, for example, heavy machinery anchor bolts, power, metallurgy, chemical equipment installation, concrete structure reinforcement renovation project [10-12]. In the case of ordinary cement grouting materials, the strength of the slurry is high due to the large water-cement ratio, the stability of the slurry is poor, and the bleeding is serious. Therefore, the high strength and high performance cement Foundation grouting material is imperative.

In this paper, we study the incorporation of nano-SiO2 in ordinary cement and fast-hard sulphoaluminate cement, filling the gap between the cement particles with nano-sized $\mathrm{SiO} 2$ smaller than the cement particle size, so that the density of the whole gel system The results show that the strength of cement-based grouting material is studied by using water-reducing agent, nano-SiO2, ordinary portland cement and fast-hard sulphoaluminate cement complex system. The effects of nano - SiO2 on the strength of grout were studied. The effects of nano - SiO2 on the strength of grout were studied. The effects of nano - SiO2 on the strength of grouting material were studied by the effect of nano - $\mathrm{SiO} 2$ on the flexural strength and compressive strength of cement - based grouting material at $4 \mathrm{~h}, 1 \mathrm{~d}, 7 \mathrm{~d}$ and $28 \mathrm{~d}$.

\section{Test Content and Method}

The cement used in this test is the ordinary portland cement produced by Xinlong City Shuanglong Building Material Co., Ltd., namely P · O42.5 and the fast-hard sulphoaluminate cement produced by Xinmi City Jianwen Special Material. 5. Test using Xuancheng Jingrui New Materials Co., Ltd. production of nano-SiO2, the average particle size of $50 \mathrm{~nm}$, recorded as NS50. The chemical composition of ordinary Portland cement, fast hard sulphoaluminate cement and nano-SiO2 is shown in Table 1. The use of the water-reducing agent for the production by the Jinan Science and 
Technology Co., Ltd. sunny days, the appearance of white powder, chloride content of less than $0.03 \%$, the total amount of less than 5\%. The standard parameters of standard sand and standard sand are shown in Table 2. The water used in the test is laboratory tap water. The specific proportions of the cement-based grouting materials to be studied in this paper are shown in Table 3.

Table 1 Chemical composition of ordinary portland cement, sulphoaluminate cement, and NS50

\begin{tabular}{|c|c|c|c|c|c|c|c|}
\hline \multirow{2}{*}{ Material } & \multicolumn{7}{|c|}{ chemical composition (\%) } \\
\hline & $\mathrm{SiO}_{2}$ & $\mathrm{Al}_{2} \mathrm{O}_{3}$ & $\mathrm{Fe}_{2} \mathrm{O}_{3}$ & $\mathrm{CaO}$ & & $\mathrm{MgO}$ & $\mathrm{SO}_{3}$ \\
\hline P.042.5 & 15.80 & 5.47 & 2.72 & 48.00 & & 2.13 & 1.59 \\
\hline R.SAC42.5 & 4.23 & 11.60 & 0.97 & 42.96 & & 2.34 & 13.58 \\
\hline NS50 & 68.26 & - & - & - & & - & - \\
\hline \multicolumn{8}{|c|}{ Table 2Particle size distributions of ISO-standard sand } \\
\hline \multicolumn{2}{|c|}{ Sieve size (mm) } & 2.0 & 1.6 & 1.0 & 0.5 & 0.16 & 0.08 \\
\hline \multicolumn{2}{|c|}{ Sieve margin (\%) } & 0 & $7 \pm 5$ & $33 \pm 5$ & $67 \pm 5$ & $87 \pm 5$ & $99 \pm 5$ \\
\hline
\end{tabular}

Table 3 Mix proportion of different cement mortars with NS50

\begin{tabular}{cccccccc}
\hline & & \multicolumn{5}{c}{ Mixing ratio of cement - based grouting material } \\
\cline { 3 - 8 } $\begin{array}{c}\text { NS50 } \\
(\text { wt\% })\end{array}$ & $\begin{array}{c}\text { Water-ce } \\
\text { ment } \\
\text { ratio }\end{array}$ & $\begin{array}{c}\text { water } \\
(\mathrm{ml})\end{array}$ & $\begin{array}{c}\text { P.O42.5 } \\
(\mathrm{g})\end{array}$ & $\begin{array}{c}\text { R.SAC42.5 } \\
(\mathrm{g})\end{array}$ & 砂 $(\mathrm{g})$ & $\begin{array}{c}\text { WS50(g) } \\
\text { Nater }\end{array}$ & $\begin{array}{c}\text { reducing } \\
\text { agent } \\
(\mathrm{g})\end{array}$ \\
\hline 0 & 0.35 & 87.5 & 160 & 90 & 500 & - & 5 \\
1.0 & 0.35 & 87.5 & 157.5 & 90 & 500 & 2.5 & 5 \\
3.0 & 0.35 & 87.5 & 152.5 & 90 & 500 & 7.5 & 5 \\
5.0 & 0.35 & 87.5 & 147.5 & 90 & 500 & 12.5 & 5 \\
\hline
\end{tabular}

The mixing method of the cement-based grouting material is as follows: The material required for the test is weighed with a precision of $0.1 \mathrm{~g}$, and the water reducing agent is mixed with the cement. The NS50 and the appropriate amount of water are stirred in the glass to the suspension. Dry can mix the cement and water-reducing agent into the mixing pot, and then the suspension into the mixing pan, and finally the remaining water into the mixing pot, the mechanical stirring. Start mortar mixer, the first slow turn after 30s sand, sand to 60s after the start fast turn, then turn 60s after 60si, and finally turn to 240s made of cement-based grouting material. Cement mortar mixer shown in Figure 1.

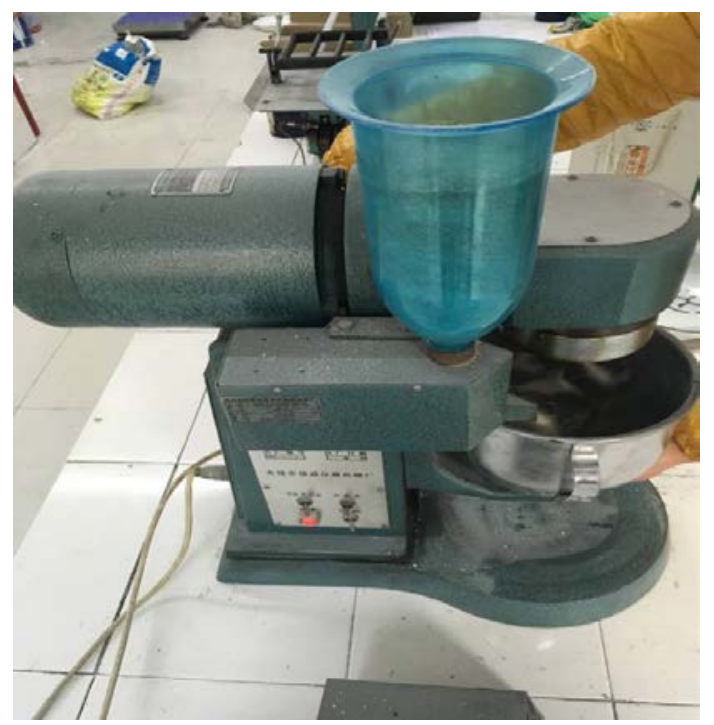

Fig.1 Cement mixer

The preparation of cement-based grouting material is as follows:

1) according to the test requirements to determine the proportion of each material weighing, prepared cement-based grouting material;

2) the cement-based grouting material in two layers into the test mode: the first layer after the 
use of feeder to scrape the surface, start the vibration table, vibration 60 times to stop; then the same into the second layer, vibration 60 Stop, as shown in Figure 2.

3) Remove the test die from the vibration table, with steel ruler along the vertical direction using sawing action scratched the surface, made $40 \mathrm{~mm} \times 40 \mathrm{~mm} \times 160 \mathrm{~mm}$ specimen, as shown in Figure 3.

4) the specimen into the curing room (20 $\pm 2{ }^{\circ} \mathrm{C}$, relative humidity greater than $90 \%$ ) for standard maintenance, maintenance to the specified time demolition; as shown in Figure 4.

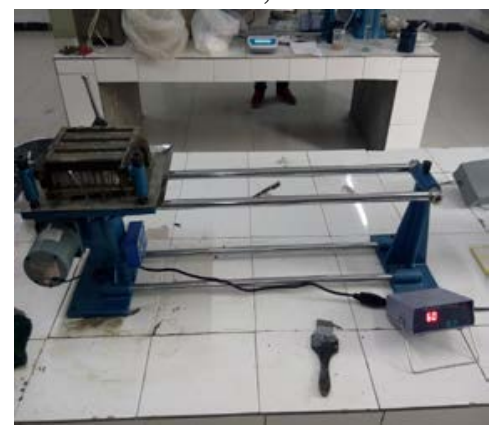

Fig.2 Cement mortar vibration compaction equipment

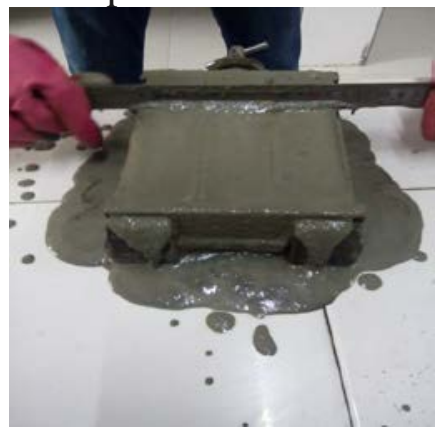

Fig.3 Preparation of the samples

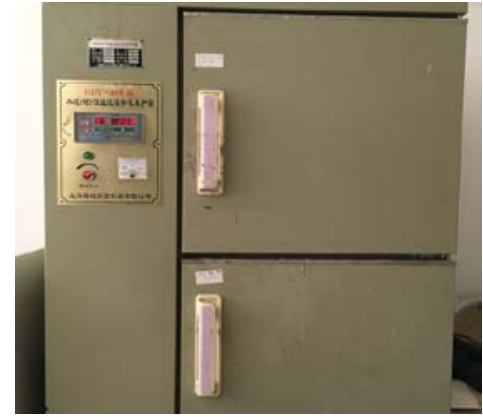

Fig.4 Constant temperature and constant wet box

In this test, the TYE-300 pressure testing machine is used to test the flexural and compressive strength of the cement-based grouting material. Note that the specimen is placed along the side of the pouring, and the flexural and compressive Strength of the value. Cement mortar anti-compression test machine as shown in Figure 5.

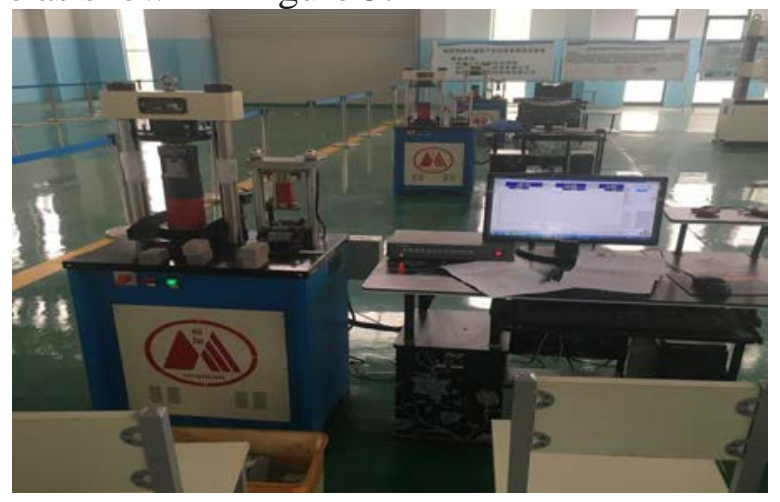

Fig. 5 Pressure testing machine of TYE-300 type

\section{Test Results and Analysis}

In this paper, the flexural strength of the cement-based grouting material for different curing ages is tested and analyzed. The results are shown in Table 4. The flexural strength of the cement-based grouting material is shown in Fig.

Table 4 Flexural strength of the cement-based grouping materials (MPa)

\begin{tabular}{|c|c|c|c|c|}
\hline year Group & JZ & NS50/1.0 & NS50/3.0 & NS50/5.0 \\
\hline 4h & 2.0 & 2.2 & 2.4 & 2.1 \\
\hline 1d & 3.7 & 5.33 & 3.33 & 3.0 \\
\hline 7d & 7.8 & 11.17 & 10.4 & 5.6 \\
\hline 28d & 9.13 & 12.01 & 11.12 & 5.95 \\
\hline
\end{tabular}

From Table 4 and Figure 6, when the nano-SiO2 content of 1.0\%, the cement-based grouting 1d, $7 \mathrm{~d}$ and 28d flexural strength are the largest, respectively, 5.33,11.17 and 12.01MPa, compared with non-doped nano-silica The growth rate of the basal medium (control group, hereinafter referred to as the control group) was $44.1 \%, 43.2 \%$ and 31.5 respectively. The early flexural strength increased rapidly. When the content of nano-SiO2 is $3.0 \%$, the early strength of cement-based grouting is growing slowly and slightly lower than that of cement-based grouting material without nano-SiO2, but the flexural strength of cement-based grouting is faster And the content of nano-SiO2 was 3.0\%, 
the flexural strength of cement-based grouting was increased by 33.3\% compared with the control group. When the content of nano-SiO2 is $5.0 \%$, the flexural strength of cement-based grouting with nano-SiO2 is reduced by $34.8 \%$.

Effect of Nano - SiO2 on Compressive Strength of Cement - based Grouting Material

The compressive strength values of cement-based grouting materials with different mixing ratios are shown in Table 5, and Fig. 7 shows the variation of compressive strength of cement-based grouting materials with different proportions.

Table 5 Compressive strength of the cement-based grouping materials (MPa)

\begin{tabular}{|c|c|c|c|c|}
\hline Group & JZ & NS50/1.0 & NS50/3.0 & NS50/5.0 \\
\hline 4h & 8.84 & 9.45 & 8.72 & 7.4 \\
\hline 1d & 19.93 & 38.62 & 19.25 & 14.68 \\
\hline 7d & 34.9 & 52.77 & 42.42 & 26.87 \\
\hline 28d & 48.83 & 55.34 & 49.12 & 35.33 \\
\hline
\end{tabular}

It can be seen from Table 5 and Figure 7 that the compressive strength of cement-based grouting in the age of $4 \mathrm{~h}, 1 \mathrm{~d}, 7 \mathrm{~d}$ and $28 \mathrm{~d}$, with the nano-SiO2 content changes, cement-based grouting material compressive strength is also large the same. When the content of nano-SiO2 is $1.0 \%$, the compressive strength of cement-based grouting material is the largest, and the strength of the cement-based grouting material is increasing with the increase of age, and it is in accordance with the requirement of later strength. And the compressive strength of cement-based grouting material increased obviously. The compressive strength growth rates of cement-based pulp were 93.8\%, $51.2 \%$ and $13.3 \%$ at $1 \mathrm{~d}, 7 \mathrm{~d}$ and $28 \mathrm{~d}$ respectively, and the compressive strength values were 38.62, 52.77 and $55.34 \mathrm{MPa}$ The When the content of nano-SiO2 was 3.0\%, the compressive strength of cement-based grouting was only increased at 7 days, and the flexural strength of cement-based grouting was similar to that of the control group. When the content of nano - SiO2 was 5.0\%, the compressive strength of cement - based grouting was lower than that of the control group, and the compressive strength of cement - based grouting was decreased by $27.6 \%$ compared with the control group.

Adding the right amount of $\mathrm{SiO} 2$ nano-powder, hydrate growth is complete, the number of more, close structure. The reason is the surface effect of nano-SiO2 powder [15]. It is easy to induce the formation of $\mathrm{Ca} 2+, \mathrm{Si} 6+, \mathrm{Al} 3+, \mathrm{Fe} 3+$ ions in the cement particles and the formation of water in the cement particles due to the small particle size and the number of atoms on the surface. The number of atoms in the surface is reduced and the atomic coordination is insufficient to make the surface atoms have high activity. More hydrates, which is the "nano-induced hydration effect." Under this effect, the hydrates of nano-SiO2 cement form a complete compact system and thus have high strength. Nano-SiO2 powder is distributed in the hydrate, filling the gap of hydrate. These ultrafine powders can also block the main pore channels between the cement particles, reduce the rate of migration of internal water and reduce the porosity. In addition, the adhesion of nano-SiO2 powder soft agglomeration can cement cement hydrate into a complete structure of the system, improve the density, is conducive to the strength of the increase. However, when the excessive amount of SiO2 nanopowder is incorporated, since these powders have a large specific surface area, the water absorption capacity is strong, and the hydration reaction is hindered. The hydration reaction is incomplete and the amount of hydrate formation is reduced. Loose, so that the intensity decreased.

When the nano-SiO2 and cement composite, nano-SiO2 smaller sphere filled with cement particles, and cement to form a better particle gradation, nano-SiO2 can be filled in the smaller gaps, faster and more effective It is possible to improve the interface between the cement hardened slurry and the aggregate faster and more effectively, and to refine the calcium hydroxide grains more effectively, thereby improving the physical mechanics of the grouting material. Performance and durability.

The effect of nano-SiO2 on the strength of cement-based grouting material is mainly reflected in 
the early stage, and the effect on the later stage is not significant. This is mainly due to the early nucleation of nano-SiO2, which promotes the early crystallization of cement hydration. Increased early strength. The nucleation of nano-SiO2 depends mainly on the number of nucleation points, the more the number of early nucleation points, the more obvious the role of nuclei. However, due to the size of $\mathrm{SiO} 2$ is too small, easy to reunite into groups, making the actual nucleation point down, can not play a very good role in the nucleus, affecting the early cement-based grouting material strength. For the late strength, the size of the crystal nucleus can not continue to grow, is not conducive to the growth of cement-based grouting material strength, resulting in cement-based grouting material strength growth is slow. However, due to the increase in the content of nano-SiO2 powder, cement water demand will also increase sharply, so the cement nano-SiO2 powder content is too high but will reduce the strength of grouting material.

It can be seen from the above analysis that when the nano-SiO2 content of $1.0 \%$, the cement-based grouting material flexural strength and compressive strength are large, while saving nano-materials, cement-based grouting material flexural strength and compressive strength also improve. We can also find that the flexural strength and compressive strength of the cement-based grouting material increase with the increase of the age, and the increase rate is also large, both in the early and late. As the content of nano-SiO2 powder increases, the cement water demand will increase sharply, and the nano-SiO2 powder is easy to agglomerate, should not be dispersed evenly, resulting in nano-SiO2 volcanic ash activity failed to fully play, affecting the cement hydration process. Therefore, the content of nano-SiO2 powder in cement is too high, but will reduce the bending strength and compressive strength of grouting material.

\section{Conclusion}

The early strength and late strength of the cement-based grouting material are greatly improved after the incorporation of nano-SiO2, but the early strength and the late strength of the cement-based grouting material decrease with the increase of nano-SiO2 powder content.

When the incorporation of nano-SiO2 is less, it promotes the hydration of cement, which makes the interface transition zone more dense and improves the flexural strength and compressive strength of cement-based grouting.

When the nano-SiO2 content is $1.0 \%$, the optimum dosage is saved, while the nano-materials are saved and the flexural strength and compressive strength of the cement-based grouting material are greatly improved.

\section{References}

[1] Ye Qing, Zhang Zenan, Kong Deyu, Chen Rongsheng, MA Chengchang Comparison of Properties of Nano-SiO2 and Silicon-doped High Strength Concrete [J] Journal of Building Materials, 2003 (6) 4: 381-385.

[2] Song Xiaojie. Application of nanomaterials in new concrete materials [J]. Journal of Anhui Institute of Architecture \& Industry, 2007 (15) 8: 22-24

[3] Li Xinyu, Fang Kunhe Research progress on the effect of silicon powder on the microstructure of hardened cement slurry [J]. Chinese Journal of Ceramics, 2003: 54-58

[4] Yao Wu, Wu Keru. Research status and development trend of intelligent concrete [J]. New Building Materials, 2000,10: 22-24

[5] Lu Tianqi. Experimental study on mechanical properties of gravel soft rock reinforced by chemical grouting [J]. Geotechnical Engineering, 2006,9 (10): 27-30

[6] Xu Qinglei. Effect of nano-silica on the performance of cement-based materials and its mechanism [D] Hangzhou: Zhejiang University

[7] Song Xiaojie. Application of nanomaterials in new concrete materials [J]. Journal of Anhui Institute of Architecture \& Industry (Natural Science Edition) 2007 (15) 8: 22-24 
[8] Xiao Mingxiu, Dong Jun. Experimental analysis of compressive strength of clay solidified slurry [J] .New Technology \& Technology, 2008, (23): 15-18

[9] Li Guhua. Effect of nanomaterials on the durability of concrete [M] Southwest Jiaotong University 2006

[10] Zhang Mei, Chen Huanchun, Yang Xujie. Nano-materials research status and prospects [J] Missile and space carrying technology, 2002 (3)

[11] Yu Hong. Nanomaterials and their application prospects [J] Hangzhou Chemical Industry.

[12] Hui Li, Hui-gang Xiao, Jie Yuan, Jinping Ou Microstructure of cement mortar with nano-particles [J] .Composite Part B: engineering 35 (2004): 185-189

[13] Byung-Wan Jo, Chang-Hyun Kim, Ghi-ho Tae, Jong-Bin Park Characteristics of cement mortar with nano-SiO2 particles [J] .Construction and building materials 21 (2007): 1351-1355

[14] Mounir Ltifi, Achraf Guefrech, Pierre Mounanga, Abdelhafid Khelidj Experimental study of the effect of addition of nano-silica on the behaviour of cement mortars [J]. Proceda Engineering 10 (2011): 900-905

[15] Fan Jijun, Cong Liqing, Tang Junyan. Nano-SiO2 to improve the mechanism of compressive strength of cement [J]. See: China Silicate Society 2003 annual meeting of cement-based materials Proceedings. Beijing: China Geological Publishing House, 2003: 451-455 